\title{
La imparcialidad en la imposición de sanciones a los servidores públicos en Colombia en la Ley 734 de $2002^{*}$
}

Impartiality in the Imposition of Sanctions on Public Servants in Colombia in Law 734 of 2002

A imparcialidade na imposição de sanções aos servidores públicos na Colômbia na Lei 734 de 2002

\author{
NATALIa CARMONA GiRALDO
}

FECHA DE RECEPCIÓN: 24 DE NOVIEMBRe DE 2020. FeCHA DE APROBACIÓN: 27 DE ABRIL DE 2021

Doi: https://doi.org/10.12804/revistas.urosario.edu.co/sociojuridicos/a.9971

Para citar este artículo: Carmona Giraldo, N. (2021). La imparcialidad en la imposición de sanciones a los servidores públicos en Colombia en la Ley 734 de 2002. Revista Estudios Socio-Jurídicos, 23(2), 11-33. https://doi. org/10.12804/revistas.urosario.edu.co/sociojuridicos/a.9971

\section{RESUMEN}

El régimen disciplinario como elemento básico de la organización estatal para cumplir los fines del Estado social de derecho presenta problemas respecto al principio de imparcialidad en los procesos que se adelantan en contra de los servidores públicos. Dicho principio es vulnerado por la misma norma, que otorga amplias facultades a la Procuraduría General de la Nación. En el presente artículo se abordará el origen del problema, se definirá la imparcialidad desde las visiones de la Corte Constitucional y la Corte Interamericana de Derechos Humanos (Corte IDH) y, por último, se hará un estudio de caso jurisprudencial del principio de imparcialidad. Se tratará de explicar el ejercicio del principio de la imparcialidad en la imposición de sanciones a los servidores públicos en Colombia en la Ley 734 de 2002, mediante el análisis de fuentes y revisión de datos a través del método descriptivo-analítico y bibliográfico o documental, lo que sin duda dará al lector un panorama de la importancia del tema.

Palabras claves: principio de imparcialidad; régimen disciplinario; servidor público.

* El presente artículo es resultado de la elaboración del proyecto de investigación en el marco de la Maestría en Derecho Público de la Universidad de Caldas. Año 2020.

** Abogada, Especialista en Derecho Administrativo. Magister en Derecho Público. Universidad de Caldas. Correo electrónico: nataliac.abogada@gmail.com 


\section{ABSTRACT}

The disciplinary regime as a basic element of the state organization to fulfill the purposes of the Social State of Law presents several problems with respect to the principle of impartiality in the processes advanced against public servants. That same rule violates the impartiality principle by granting broad powers to the Attorney General's Office. The article will address the origin of the problem, define impartiality from the Colombian Constitutional Court's and the Inter-American Court of Human Rights' points of view, and, finally, it will present a case study. The article will try to explain the exercise of the principle of impartiality in the imposition of sanctions to public servants in Colombia according to Law 734 of 2002, through the descriptive-analytical and bibliographic or documentary method, which will undoubtedly provide the reader with an overview of the importance of the subject.

Key Words: Principle of impartiality; Disciplinary Regime; public servant.

\section{RESUMO}

O regime disciplinar como elemento fundamental da organização estatal, para cumprir os fins do Estado Social de Direito, no que diz respeito ao princípio da imparcialidade nos processos que sejam instaurados contra os servidores públicos, princípio que é violado pela mesma norma, que confere amplos poderes à Procuradoria Geral da Nação. No presente artigo será abordada a origem do problema, a imparcialidade será definida a partir da visão do Tribunal Constitucional e da Corte Interamericana de Direitos Humanos, e, finalmente, será apresentado um estudo de caso jurisprudencial do princípio de imparcialidade; procurar-se-á explicar o exercício do princípio da imparcialidade na imposição de sanções aos servidores públicos na Colômbia na Lei 734 de 2002, por meio da análise de fontes e revisão de dados, por meio do método descritivo analítico e bibliográfico ou documental, que sem dúvida, dará ao leitor um panorama geral da importância do assunto.

Palavras-chave: princípio da imparcialidade; regime disciplinar; servidor público. 


\section{Introducción}

El derecho disciplinario en Colombia presenta problemas como la falta de competencia y celeridad de los procesos, la impunidad de las faltas disciplinarias, la violación al debido proceso y la comprobación de la real afectación de los fines del Estado. Dado que la ley disciplinaria ha sido objeto de modificaciones legislativas y aún sigue teniendo auge en los cambios, el operador disciplinario se limita a las fallas en el servicio del ejercicio de una función. Esto hace que la esencia del derecho disciplinario sea entonces la de tener una función preventiva y correctiva, más que sancionatoria, a la luz del artículo 16 de la Ley 734 de 2002, que lleva a olvidar el real atributo del derecho disciplinario: velar por la protección de los derechos de las personas, respetando el principio de imparcialidad, que protege los fines del Estado social de derecho.

La presente investigación jurídico-descriptiva tratará de abordar la descripción del sistema de control disciplinario analizando dicha figura en tres estadios: (i) Origen del problema; (ii) Definición de la imparcialidad a la luz de la Corte Constitucional y la Corte Interamericana de Derechos Humanos (Corte IDH), y (iii) Un estudio de caso jurisprudencial del principio de imparcialidad.

Para ello, se utilizó una variedad de instrumentos y métodos: recolección de datos sobre la temática abordada en el derecho disciplinario en sentencias y fuentes primarias y secundarias como normatividad, jurisprudencia, doctrina, artículos y libros, entre otros. No obstante, por la gran cantidad de información no fue posible abordarla toda.

La potestad del Estado para castigar los comportamientos que contraponen la estructura de orden constitucional no solo de los particulares, sino en especial de quienes desempeñan funciones públicas, que por supuesto no escapa a los postulados del orden social, se delega en la Procuraduría General del la Nación y en las oficinas de control disciplinario que, por la falta de estructura de un sistema de pesos y contrapesos, afecta la materialización de los derechos de los disciplinados, en lo relacionado con el principio de imparcialidad, que muestra un matiz de alto contenido político.

La presente investigación pretende hacer un aporte al acervo académico institucional, toda vez que el tema es de suma importancia 
para el Estado; el control social ha desempeñado un papel esencial a lo largo de la historia. Las sociedades han ido evolucionando y crean sus propios postulados, valores y principios; el derecho es el camino para la protección de estos preceptos sociales, que permite generar un servicio social, en la medida que se reconoce como ciencia humana que busca el control general de las personas. A esto se le suman los diferentes tipos de poder, esto es, la administración en cabeza del Estado social de derecho, que busca preservar los fundamentos con los que se constituye y representa lo más valioso para una sociedad.

\section{Origen y desarrollo histórico del principio de imparcialidad: la imposición de sanciones a los servidores públicos en Colombia}

El hombre siempre ha intentado explicar los comportamientos humanos, de allí que se establezcan unos valores y principios sociales (Rousseau, 1778). De acuerdo con la necesidad de cada organización, algunos se quedan en características netamente de comportamiento ético (pecados) y otros van a estructurarse como principios fundantes de una sociedad (delitos). En los primeros hay libertad de conciencia, en los segundos hay una imposición de orden y un llamado a cumplirlos, porque de no hacerlo deviene un castigo o una sanción.

Antes de definir el servicio público resulta importante hacer las siguientes acotaciones: el Estado surge cuando se crean necesidades de organización estatal conforme a las prioridades de cada sociedad, esto es importante porque el punto que se quiere mirar es que al principio los primeros conceptos de organización estatal estaban más ligados a lo divino y fantasioso. Así, el poder venía de Dios, luego entonces, Dios elegía a un súper hombre y este representaba al Estado -en estas primeras sociedades, el concepto de Estado se entiende como la forma de representación política-. Así mismo, hay que hablar de una forma de organización especial de personas que representaban el poder del supremo (Maquiavelo, 1895), quien, a su vez, les ordenaba y siempre estaba por encima de ellos: 
Los llamados pecados nefandos, que eran los delitos más graves que existían en la Edad Media, verbigracia el adulterio, la bestialidad, la sodomía, el incesto y el suicidio, obligaban en conciencia, lo que implicaba responsabilidad subjetiva (...) al lado de los delitos existía lo que hoy podríamos llamar, a grandes rasgos y tentativamente, un derecho administrativo sancionador. Este tenía que ver con faltas menores y en las cuales la responsabilidad se determinaba de una manera puramente objetiva, toda vez que las leyes no obligaban en conciencia. A quien no pagaba un tributo a tiempo se le imponía una sanción; por tanto, operaba una pura responsabilidad objetiva (Gómez, 2017, p. 186).

De acuerdo con lo anterior, habrá que decir que en la Edad Media lo más importante era la fusión de lo divino con lo moral, que trajo los conceptos de pecado y obediencia a través de la conciencia; además, existían comportamientos indebidos, que hoy serían considerados como delitos, que cuando se llevaban a cabo resultaban en una sanción. Posterior a esto se empieza a ver que el que administra tiene representantes, ¿qué pasa cuando estos representantes salen de la esfera de lo ordenado por el supremo y, de una u otra manera, generan un daño? Para responder a esta pregunta es necesario hablar de la evolución del castigo, en este punto, el mismo supremo tenía a su disposición el retirar de sus funciones a quienes no cumplían su voluntad a satisfacción.

De lo anterior se colige que el castigo está asociado con el poder. Este concepto también evoluciona, piénsese en el ejemplo que describe Foucault (1975) sobre un hombre condenado por homicidio en la Edad Media: la condena que le imponían era el sufrimiento de torturas desde ser atenazado, echarle hierro caliente en sus heridas, hasta ser amarrado y desmembrado por caballos para posteriormente ser incinerado (p. 82). El castigo entonces evolucionó a preceptos sociales y conciencias colectivas, los correctivos que se aplican ahora son diferentes (Foucault, 1975, p. 82).

El castigo ha existido desde tiempos inmemorables. Cada sociedad define su propio sistema, en las sociedades medievales el derecho de castigar correspondía al soberano: "Diríase que el rey había querido con eso demostrar que el 'soberano poder' al que corresponde el derecho de 
castigar no puede en caso alguno pertenecer a 'la multitud'" (Foucault, 1975, p. 42). Al ser esto así, habrá que decir entonces que la misma administración del Estado estaba de cierto modo ligada a un ejecutivo, por llamarlo de alguna manera, que era el Monarca. Piénsese en lo especial de la situación, esto fue el inicio de un derecho disciplinario sancionador del servidor público, por supuesto estos son conceptos modernos, pero muestran la evolución de esta rama del derecho y su inevitable enlace al Estado social de derecho:

Ser servidor público es honor, responder a esa condición, es necesario, todo lo que contradiga esos postulados constitucionales de representar el Estado, debe ser castigado, fíjense que el castigo aquí, supera el cuerpo, es algo mucho más grande, es decirle a la persona "usted no representó el Estado correctamente", por tanto, no puede seguir en esa relación, eso deslegitima el Estado, como soberano y rey (Foucault, 1975, p.63).

De acuerdo con esto, se tiene que la facultad disciplinaria ha evolucionado, así como la independencia y la autonomía de esta rama (Brito, 2012). Bien pudiera decirse que hoy las sanciones son diferentes a las penales o fiscales, van más allá y están encaminadas a la protección del servicio público:

Hacer del castigo y de la represión de los ilegalismos una función regular, coextensiva a la sociedad; no castigar menos, sino castigar mejor; castigar con una severidad atenuada quizá, pero para castigar con más universalidad y necesidad; introducir el poder de castigar más profundamente en el cuerpo social (Foucault, 1975. p. 87).

Entonces, el castigo evoluciona y pasa de la retaliación y dolor físico, al control social por medio de cárceles, en respuesta a esa voluntad social al conjunto de preceptos que se consideran importantes. Se pasa del castigo en plaza pública, mediante la tortura, a procesos estructurados con derechos para las personas. La concentración del poder en el monarca (Montesquieu, 1748) empezó a causar malestar en el pueblo y, de este modo, la misma sociedad permitió cambios en la imposición de las penas. Díaz (2007) ilustra esta situación: 
Con el tiempo, esta forma de manifestar el poder punitivo se cuestionó, el pueblo se reveló contra leyes que consideró clasistas, e injustas. Se criticó por tanto no solo los privilegios de la justicia, su arbitrariedad, su arrogancia arcaica, sus derechos sin control, sino también las debilidades, sus excesos, exageraciones, lagunas, y sobre todo el sobre-poder monárquico. Todo lo anterior condujo a revaluar la forma de castigo, por el temor del poder político ante el efecto de estos rituales ambiguos (p. 150).

De lo anterior se desprende que el castigo pasó de ser una medida irracional a ciertos parámetros esquematizados, que surgieron de un excesivo poder al monarca, quien centralizaba el poder, el juzgamiento y la sanción. La arbitrariedad se vio volcada y con ello surgieron nuevas medidas para la obtención de justicia, lo que llevará a una nueva forma de vida social. Posterior a esto, se empieza a ver que quien administra tiene representantes. Estos representantes también pueden apartarse de lo ordenado por el supremo y habrá que desarrollar entonces una forma de sancionarlos.

Analizado lo anterior, es importante resaltar que luego del monarca apareció el concepto de Estado liberal (siglo XVIII). De allí viene y avanza al Estado de derecho; la sociedad pide cambios, sobre todo en la estructura del poder, esto es significativo porque luego de ellos viene el Estado social de derecho, producto de la soberanía popular y con ello la protección de los fines constitucionales a través del derecho disciplinario.

El derecho ha ido avanzando y cambiando profundamente y desde la academia se ha ido fortaleciendo. Sin embargo, hay aún muchos vacíos que reflejan la paradoja de un derecho positivo y lo que realmente se presenta (el derecho práctico).

Para los efectos de este artículo, es pertinente ver la aplicación del positivismo en el derecho disciplinario, hacer un recorrido por la historia del avance de este, centrando la mirada en autores que han definido la imparcialidad y la facultad sancionatoria del Estado. A partir de la creación de esa relación Estado-sociedad y según lo que se plantea, el mismo Estado se preguntará: ¿Quién controla al Estado? 
De lo preliminar queda claro que el derecho disciplinario, indudablemente, desentraña una potestad única por parte del Estado de castigar conductas como omisiones, extralimitaciones y prevaricatos cometidas por servidores públicos, que tampoco son permitidas en la misma sociedad, que demanda justicia y control. A lo largo de la historia, se ha hablado de sociedades con poder, del manejo de ese poder y de las sanciones a que ello da lugar; así mismo, se habla de los comportamientos aceptados por la sociedad y de los que son objeto de reproche:

El tipo penal dentro del rango normativo ha de identificarse con la ley en sentido formal, es decir que el delito, la descripción jurídica del mismo, únicamente puede emanar de una norma con características formales de ley, mientras que si bien es cierto las faltas disciplinarias responden al principio de legalidad, dada su definición abstracta, terminan concretándose en normas distintas de la ley y muchas veces de menor jerarquía desde el punto de vista técnico jurídico (Gutiérrez E Escobar, 2010, p. 220).

De esta afirmación es importante resaltar que en el derecho penal se habla de delitos, mientras que en el derecho disciplinario, de faltas disciplinarias. Así, a pesar de que el derecho disciplinario tiene sus raíces en el derecho penal, ambos son diferentes y buscan castigar por conductas también diferentes: el derecho penal se aplica a todas las personas, mientras que el derecho disciplinario solo se ejerce sobre un grupo determinado de la población, quienes tienen relación directa con el Estado: los servidores públicos y los particulares que desempeñen funciones públicas.

Para el caso colombiano, la estructura del derecho disciplinario antes de la Constitución de 1991 estaba dada por el derecho penal, un área que explora los diversos sentidos del delito, las conductas de los sujetos y el poder del Estado, que faculta a castigar ciertos comportamientos. En consecuencia, el derecho disciplinario era entendido como una subsección del derecho penal. Este sistema tenía falencias y puntos críticos: la falta severa de sanciones que permitieran a los servidores públicos entender que el sistema de prestación de servicios públicos iba más allá de solo ejercer funciones del cargo. 
Es importante destacar que el derecho disciplinario tuvo sus inicios y bases en el derecho penal, con la creación de la Ley 200 de 1995. Con esta se dieron los primeros pasos de un orden que buscaba controlar, vigilar y, si era necesario, sancionar disciplinariamente a los servidores públicos. Dicha ley, a pesar de haber sido creada bajo la Constitución Política de 1991, no logró dimensionar ni suplir las necesidades del Estado social de derecho para la protección de los valores, principios y derechos consagrados en la Carta Política.

De lo anterior, es importante destacar que el cambio más grande que se dio con la expedición de la Ley 734 de 2002 fue la notable diferencia de afectación al deber funcional, consagrado en el artículo 5 de la misma ley. Esto se dio, cabe decir, bajo la mirada de un Estado proteccionista y garantista de derechos, consagrado en la Constitución Política de 1991. Con la defensa y protección de sus principios y valores, se pretendió darle un nuevo enfoque al Código Disciplinario Único, que hoy rige en Colombia. Al respecto, Roa (2012) afirma:

Ello permite comprender, por tanto, en el orden que precede, que la ilicitud sustancial como razón de ser y eje principal de la existencia de falta disciplinaria no se materialice con el solo incumplimiento del deber funcional, sino que, necesariamente, con este se afecten o se desconozcan los principios de la función pública, los fines del Estado y los derechos fundamentales (p. 100).

El derecho disciplinario colombiano, con su régimen actual en la Ley 734 de 2002, reguló las conductas de los servidores públicos a través de su régimen de prohibiciones, derechos, deberes y régimen de incompatibilidades. Con esta ley se buscó acoplar todas las conductas de los servidores públicos y de los particulares que desempeñan funciones públicas - un intento de aplicación del derecho positivo-.

Es necesario aclarar que el proceso disciplinario a principios del año 2021 se rige por la Ley 734 de 2002, modificada por la Ley 1952 de 2019, que entrará en vigencia en junio de 2021. El trámite sigue siendo netamente administrativo, la nueva norma contempla cambios en los tiempos de indagación e investigación, y propone una serie de procedimientos en materia probatoria; sin embargo, lo que respecta al 
principio de imparcialidad sigue estando contenido en la norma anterior en los artículos 23 y 148.

La forma como está concebido el procedimiento disciplinario sigue siendo: Etapa de indagación, investigación, decreto y práctica de pruebas, cierre de investigación, formulación de pliego de cargos, alegatos de conclusión y fallo de primera instancia a cargo del director del proceso disciplinario. Es decir, no hay separación de funciones las cuales deberían considerarse en un primer momento hasta la formulación del pliego de cargos; desde ahí debería asumir la investigación otra oficina para garantizar la imparcialidad. Sin embargo, es una temática que merece ser desarrollada y estudiada a profundidad.

No hay imparcialidad cuando los recursos son resueltos por la misma entidad que profiere el auto; no hay una real defensa para considerar los argumentos presentados por la persona que está siendo investigada, simple y llanamente el fallo sancionatorio es un acto administrativo, susceptible de ser llevado a la jurisdicción contencioso-administrativa. La autonomía e independencia que tienen los jueces, no la tienen los operadores disciplinarios, es por ello que este principio de imparcialidad toma aún más relevancia, así como la división de funciones y la meritocracia. En la medida que se proteja y aplique el principio de imparcialidad se protege la democracia y los derechos de las personas.

Por el desequilibrio que se presenta actualmente en el sistema de pesos y contrapesos, nótese cómo el Procurador General de la Nación es elegido por el presidente de una terna, lo que deja de lado la meritocracia. En la meritocracia se está exento de presiones políticas y externas. No se puede materializar un principio de imparcialidad cuando la elección de quien orienta el proceso depende del ente nominador, es decir, el gobernante de turno, el ejecutivo. En las unidades de control disciplinario se nombran por el nominador los cargos de dirección del proceso, esto de cierto modo altera la total imparcialidad frente a los procesos disciplinarios, paradójicamente los servidores públicos de dicha entidad van a ser controlados y vigilados por quien representa la confianza del gobernante. 


\section{Perspectiva jurisprudencial del principio de imparcialidad desde el conflicto jurídico de la Corte Constitucional y la Corte IDH}

La Corte IDH ha sido enfática en promover la teoría del juez natural. Este órgano tiene claro que para defender los derechos humanos lo más importante es que cada competencia del juez esté claramente delimitada, pues más allá de la justicia que se imponga en cada país, están los derechos que pertenecen al ser humano por el simple hecho de existir; de allí se van a desprender formas especiales de impartir justicia, que serán generales, no importa el Estado donde se apliquen:

Desde su más temprana jurisprudencia, la Corte IDH ha determinado que los civiles no pueden ser juzgados por tribunales militares sino por el fuero común. Igualmente, se ha determinado que los tribunales militares al juzgar a civiles no cumplen los requisitos de independencia, imparcialidad, ni constituyen, para efectos de la Convención Americana, el juez natural para juzgar ese tipo de asuntos (Steiner, 2014, p. 89).

Es así como en el caso de un militar, la Corte IDH manifestó que el juez natural para juzgar ese tipo de asuntos de ningún modo podía pertenecer a la línea militar; esa imparcialidad que se exige al momento de realizar el análisis del caso se va a ver contaminada por la jerarquía y los postulados propios de los militares; esto desdibuja de cualquier modo, la protección de derechos humanos porque la competencia se encontraría en manos de un órgano que en principio ya carece de una efectiva imparcialidad:

La Corte IDH ha sostenido de forma constante que las instancias jurisdiccionales militares no son las indicadas para juzgar presuntas violaciones a derechos humanos cometidas por personal policial o militar; esto, debido a que los tribunales castrenses se encuentran insertados dentro de estructuras jerarquizadas que no son independientes ni imparciales. Asimismo, ha determinado que en este tipo de casos la investigación y sanción a los responsables debe recaer desde 
un principio en la justicia ordinaria, ya que es el juez ordinario, el juez natural para este tipo de casos (Steiner, 2014, p. 90).

De este modo la Corte IDH es una defensora del juez natural, del principio de imparcialidad, visto desde características de independencia, debido proceso y, sobre todo, de derechos humanos. López Nuila y Molina Méndez (2013) aseguran que la imparcialidad siempre va a depender del juez natural, es decir, del competente para conocer asuntos propios de cada jurisdicción. Dependiendo del Estado, de ninguna manera justicias impartidas por la misma administración, esto tiene sentido cuando Steiner (2014) refiere: " El juez encargado del conocimiento de una causa debe ser competente, además de independiente e imparcial" (p. 90).

De lo anterior, se deduce que la Corte IDH también define la importancia de la independencia del juez, aspecto significativo en el sentido de garantizar su imparcialidad al momento de tomar su decisión, responsabilizando fuertemente a los Estados cuando esa garantía se ve afectada:

En el mismo sentido, la Comisión Interamericana ha establecido que el Estado incurre en responsabilidad cuando, aún sin haber violado directamente los derechos, no efectúa una investigación seria de la privación del derecho a la vida, por un órgano independiente e imparcial (Steiner, 2014, p.119).

Es decir, que para la Corte IDH es de suma importancia que cada Estado, a través de su justicia a impartir, pueda garantizar la independencia e imparcialidad del juez, esto se puede acreditar cuando las competencias de cada Estado están bien definidas y ningún poder ajeno influye para tomar una decisión. Aquí toma relevancia el artículo 8.1. de la Convención Interamericana de Derechos Humanos:

Artículo 8. Garantías Judiciales 1. Toda persona tiene derecho a ser oída, con las debidas garantías y dentro de un plazo razonable, por un juez o tribunal competente, independiente e imparcial, establecido con anterioridad por la ley, en la sustanciación de cualquier acusación penal formulada contra ella, o para la determinación de sus derechos y obligaciones de orden civil, laboral, fiscal o de cualquier otro carácter. 
Lo anterior confirma que la imparcialidad, más que un principio, configura un derecho para toda persona sometida a la justicia (Dworkin, 2015). El mínimo de exigencia para un juez es que este goce de la independencia suficiente para que pueda obrar con imparcialidad, que se va a convertir también en una garantía del debido proceso. Esto va a permear la justicia de fallos políticos que puedan versar en asuntos propios de cada Estado.

Por otro lado, en varias oportunidades la Corte Constitucional ha dicho que el derecho disciplinario es el que protege los fines esenciales del Estado, por cuanto su finalidad es la protección de los principios constitucionales:

Dentro del marco constitucional, la función pública es el régimen que regula las relaciones jurídicas del Estado con los particulares en lo atinente a las funciones a cargo del Estado y la prestación de servicios que le asigna la Constitución y la ley, para el cumplimiento de los fines del Estado social de derecho (Sentencia C-417 de 1993).

El proceso disciplinario, al igual que cualquier otro proceso sancionador, debe estar inmerso en las categorías garantistas de la Constitución Política, de tal forma que en la medida que se ejerza la coacción administrativa se proteja a aquel ciudadano de características especiales (funcionario público) del peso y energía del Estado, quien cuenta con todos los medios de conocimiento, físicos y técnicos, para adelantar un proceso del cual hasta ahora muy poco se puede controvertir, salvo que se lleve a la instancia de control de constitucionalidad (Sentencia C-028 de 2006).

Es así como en el Estado colombiano se ha resaltado la importancia de la aplicación del principio de imparcialidad como pilar fundamental del Estado social de derecho, que salvaguarda los derechos de las personas. Como fundamento constitucional fuerte que ha protegido todas las esferas de la justicia, suelen asociársele los principios de debido proceso y de derecho a la igualdad. Incluso la Corte Constitucional ha establecido: 
La jurisprudencia de esta corporación ha puntualizado que los atributos de independencia e imparcialidad del funcionario judicial están orientados a salvaguardar los principios esenciales de la administración de justicia, y se traducen en un derecho subjetivo de los ciudadanos en la medida que forman parte del debido proceso. Los impedimentos y las recusaciones son los mecanismos previstos en el orden jurídico para garantizar el principio de imparcialidad del funcionario judicial. Tienen su fundamento constitucional en el artículo 29 de la Constitución, y en los convenios internacionales sobre derechos humanos aprobados por el estado colombiano (Sentencia C-881 de 2011).

De lo anterior hay que decir que para la Corte Constitucional es de suma importancia el factor de las recusaciones como garantía del principio de imparcialidad, pues siempre que se tengan suficientes razones se debe avalar la recusación interpuesta, ello protege el derecho del investigado y, por supuesto, responde al debido proceso (Prieto, 2003) y al acceso a la justicia.

Siguiendo esta postura, es claro que para la Corte Constitucional sí se garantiza el principio de imparcialidad porque existe otro principio del debido proceso, que trae inmerso el obrar correcto del juez, que a la hora de imponer una sanción garantiza que está apartado de todo vicio, convicción, valor propio, pensamientos e inclinaciones personales. Esto hace que a través de los impedimentos y recusaciones, los investigados tengan acceso a la materialización de la igualdad y a la garantía del considerado obrar a la hora de imponer una sanción.

Habrá que decir también que para la Corte Constitucional, la imparcialidad es considerada una condición inherente al juez. Pues bien, estas personas que se encargan de juzgar y realizar un análisis de un caso gozan de objetividad y bien van a olvidar todos sus intereses y pensamientos personales a la hora de tomar una decisión. Esto es importante en pro del desarrollo del derecho a la igualdad ante la ley que tienen todas las personas, es decir, que para la Corte Constitucional el principio de imparcialidad es un pilar fundamental que ayuda a comprender y materializar otros principios y derechos constitucionales: 
Por su parte, la imparcialidad se predica del derecho de igualdad de todas las personas ante la ley (Art. 13 C.P.), garantía de la cual deben gozar todos los ciudadanos frente a quien administra justicia. Se trata de un asunto no sólo de índole moral y ética, en el que la honestidad y la honorabilidad del juez son presupuestos necesarios para que la sociedad confíe en los encargados de definir la responsabilidad de las personas y la vigencia de sus derechos, sino también de responsabilidad judicial. El logro de estos cometidos requiere que tanto los jueces como los demás profesionales del derecho se comprometan en los ideales y el valor de la justicia, para lo cual no basta el simple conocimiento de la ley y del procedimiento, sino que es indispensable el demostrar en todas las actuaciones judiciales los valores de la rectitud, la honestidad y la moralidad" (Sentencia C-037 de 1996).

De lo anterior queda claro que, para la Corte Constitucional los valores de rectitud, honestidad y moralidad son características que se le atribuyen al juez y que se dan por supuestas cuando existe una decisión. Si bien es importante el conocimiento procedimental y legal, son exigencia inherente a la de realizar el ejercicio de impartir justicia las condiciones que apunten a la aplicación del principio de imparcialidad. El deber ser de la justicia y lo que esperan los ciudadanos y el conglomerado social frente a las actuaciones de cualquier jurisdicción es que a través de sus representantes se materialicen los derechos y los principios constitucionales.

\section{La aplicación del principio de imparcialidad en Sentencia de Unificación 712/13 (Caso Piedad Córdoba)}

Algunos autores como Ardila (2010) y Daza (2011) manifiestan que el derecho disciplinario es considerado como un derecho independiente y autónomo del derecho penal, que va más allá de ser un derecho sancionador y es más bien un cuidador de los postulados constitucionales. Al respecto, Gómez (2008) afirma: "Para entender sustancialmente quebrantado el deber se requiere que la conducta enjuiciada haya desconocido no solo el ropaje jurídico del deber, sino 
también la razón de ser que el mismo tiene en un Estado social y democrático de derecho" (p. 9).

A pesar de la creación de un régimen jurídico que contenía un orden que buscaba controlar, vigilar y, si era necesario, sancionar disciplinariamente a los servidores públicos, la Ley 734 de 2002 no logró dimensionar ni suplir las necesidades del Estado social de derecho consagradas en la Carta Política del 91.

Por ello fue necesaria la intervención del Estado en un escenario de verdadera equidad, porque a pesar de que la ley cobija bastas situaciones, son las altas cortes las encargadas de dilucidar y garantizar la realización de la justicia en la aplicación de la norma a minorías. Por ello, la intervención activa en estas esferas resulta trascendental, pues implica una materialización de la igualdad de las personas y la protección de los postulados constitucionales:

El cambio de concepción de la igualdad formal a la igualdad material, propio del Estado Social de Derecho, según el cual la autoridad pública no sólo protege el derecho mediante la abstención sino también y, en algunas oportunidades en forma obligatoria, mediante la intervención activa en esferas específicas, generó decisiones públicas proteccionistas de grupos de personas que han sido tradicionalmente marginados o discriminados por razones diversas. En tal virtud, la aplicación efectiva y real del principio de igualdad en el constitucionalismo contemporáneo exige del Estado su intervención, de un lado, para evitar que los agentes públicos y los particulares discriminen y, de otro, para hacer exigibles tratos favorables en beneficio de personas que se encuentran en situación de debilidad manifiesta (Sentencia C-932/07).

Asimismo, la Corte Constitucional ha sido enfática en la importancia de la imparcialidad del juez o funcionario al momento de tomar una decisión:

El derecho a la independencia del juez, que solo tiene efectivo reconocimiento cuando los servidores públicos a los cuales confía la Constitución la tarea de administrar justicia, ejercen funciones separadas de aquellas atribuidas al ejecutivo y al legislativo (...) El derecho a la imparcialidad del juez, funcionario que siempre deberá decidir 
con fundamento en los hechos, de acuerdo con los imperativos del orden jurídico, sin designios anticipados ni prevenciones, presiones o influencias ilícitas (Sentencia T-001 de 1993).

Por esa misma línea, la Corte Constitucional colombiana ha dicho que:

La aplicación de la Convención Americana debe tener en cuenta la arquitectura institucional de cada Estado, esto es, del contexto en el que se inserta, como lo reconoce la Convención al indicar que corresponde a la ley reglamentar el ejercicio de los derechos políticos y el mecanismo de sanción (Sentencia SU712/13).

Analizado el caso en la Sentencia SU712/13, que versa sobre la destitución de una congresista e inhabilidad por el término de 18 años, resulta evidente el quebrantamiento del principio de imparcialidad en el Estado social de derecho, que sucede porque la Corte Constitucional, al analizar la tutela incoada por dicha servidora pública, hizo un estudio formal y no material del derecho que ella tenía. Esto sucedió porque la Corte, aduciendo que es consciente de que el sistema de pesos y contrapesos no funciona correctamente, no es quien para corregirlo:

La sanción disciplinaria no implica en sí misma la existencia de un perjuicio irremediable, porque de lo contrario se despojaría de sus atribuciones al juez ordinario ante una decisión que prima facie es consecuencia de la conducta del servidor público y por lo tanto afectación legítima de sus derechos (Sentencia SU712/13).

En la misma sentencia, la Corte dijo que la acción de tutela era procedente si se daban las siguientes características: (i) Motivos serios y razonables debidamente argumentados en pro de la violación al debido proceso; (ii) Perjuicio en el ejercicio de un derecho fundamental; (iii) Debe tratarse de un daño cierto, inminente, grave y de urgente atención; (iv) Exista un perjuicio irremediable grave, y (v) Que los medios ordinarios de defensa no sean suficientemente expeditos. Es decir, primero le da razón en aceptar la revisión de la tutela, diciendo que es procedente, también dice que está de acuerdo en que el sistema funciona mal, para 
luego simplemente manifestar que no tiene facultades legislativas, así que el competente debe resolver el asunto.

Es por ello que en Colombia se habla de imparcialidad; la realización efectiva material de los derechos y de los principios, en este caso del principio de imparcialidad, es paradójica, constitucionalmente se define que la competencia disciplinaria y sancionatoria está perfecta, por cuanto está contenida en la Constitución. Al respecto, la Corte manifestó: "las competencias disciplinarias y sancionatorias del Procurador General de la Nación no desconocen el artículo 93 de la Constitución, ni el artículo 23 de la Convención Americana sobre Derechos Humanos" (Sentencia SU712/13).

Pero acto seguido, la misma Corte Constitucional manifiesta que dichas sanciones pueden ser objeto de revisión en lo contenciosoadministrativo o a través de tutela ante la Corte Constitucional:

la Corte debe recordar que la decisión sancionatoria ha de ser adoptada en el marco de un proceso administrativo, sujeto a las garantías que se reconocen a dichas actuaciones tanto por la Constitución como por los instrumentos internacionales que se integran a ella; y en todo caso es susceptible de ser sometida a control judicial ante la más alta autoridad de la jurisdicción contencioso administrativa, o excepcionalmente por el juez constitucional a través de la acción de tutela (Sentencia SU712/13).

Entonces, en Colombia existe independencia disciplinaria, sin que esto quiera decir que serán definitivas las decisiones que se adopten en esa sede administrativa. Si bien la Corte Constitucional considera que, efectivamente, existen falencias en un sistema ideal de pesos y contrapesos, corresponde al legislador, por separación de competencias, determinar las sanciones. Al respecto se encuentra lo siguiente:

La Corte reconoce que el juzgamiento disciplinario de los Congresistas de la República por parte del Procurador General de la Nación presenta imperfecciones en un sistema ideal de pesos y contrapesos, aun cuando, en su condición de juez constitucional, carece de atribuciones para corregir esas imperfecciones, implementar las reformas o adoptar los correctivos a que haya lugar (Sentencia SU712/13). 
Respecto a lo anterior, es interesante analizar cómo en un Estado social de derecho, donde se materializan los derechos, constitucionalmente se niegan los mismos por falta de legislación, incluso cuando en la misma Corte Constitucional lo mencionan en los salvamentos de voto de la Sentencia SU712-13:

Los pilares esenciales de la función jurisdiccional en un Estado democrático de derecho son la independencia, la autonomía y la imparcialidad. Esos tres principios operan como garantía insustituible para todo aquel que deba enfrentarse o discutir un asunto ante la administración de justicia, y vienen a completar el complejo de garantías comprendido bajo el concepto de debido proceso. Ello explica que los procedimientos que pueden ocasionar interferencias particularmente graves en los derechos ciudadanos se atribuyan a autoridades judiciales. [...] La ausencia de normas especiales, adecuadas a este escenario constitucional y la inexistencia de controles efectivos a decisiones que suponen una intensa afectación a los derechos políticos, indican que la competencia bajo análisis supone una facultad que escapa a los límites de proporcionalidad y razonabilidad que la Constitución exige a toda intensa interferencia en los derechos fundamentales (Sentencia SU712-13 Salvamento voto, Luis Hernesto Vargas Silva).

Finalmente, en este caso se evidencian los riesgos de insuficiente imparcialidad a la hora de aplicar sanciones disciplinarias (Forero, 2009) y la precariedad de disposiciones legales suficientes que garanticen y legitimen la efectividad material del principio de imparcialidad en un Estado que en este caso no resulta ser social, sino político (Schimitt, 1932). Al respecto se encuentra:

Se añade que el proceso se sigue contra un congresista, los riesgos de insuficiente imparcialidad se incrementan, pues al Procurador lo elige el Senado, y el constitucionalismo colombiano ha considerado razonablemente que esto acarrea problemas desde la perspectiva del derecho a un proceso imparcial, cuando quien funge como procesado pertenece a su turno al órgano elector (el Congreso) (...) PRINCIPIO DE IMPARCIALIDAD EN PROCESO DISCIPLINARIO DE CONGRESISTA-Se ve 
afectado por la elección del Procurador General por parte del Congreso (Sentencia SU712-13 Salvamento de voto, María Victoria Calle).

Corolario de lo anterior, en definitiva, hay que mencionar que se obtiene un grado de verdad y de justicia en la jurisdicción de lo contencioso-administrativa, donde se declaró la nulidad de la sanción impuesta a la servidora pública, a través del Consejo de Estado, donde manifiestan que dicha jurisdicción ejerce un control judicial integral a los fallos sancionatorios disciplinarios:

La jurisdicción de lo contencioso administrativo ejerce el control judicial integral 79 de los actos administrativos sancionatorios, proferidos por los titulares de la acción disciplinaria regulada en la ley 734, con el fin de garantizar la tutela judicial efectiva. 2. El control que ejerce la jurisdicción de lo contencioso administrativo, constituye el recurso judicial efectivo en los términos del ordinal $1 .^{\circ}$ del artículo 25 de la Convención Americana de Derechos Humanos (Sentencia No. 11001032500020110031600 de fecha 9 de agosto de 2016).

Lo anterior genera muchas dudas respecto a cuántas jurisdicciones tienen en realidad estos actos administrativos de carácter sancionatorio, y cuál jurisdicción está materializando los derechos de este tipo de personas. El principio de imparcialidad en el régimen disciplinario de los servidores públicos en Colombia como Estado social de derecho carece de efectividad material, debido a que no hay un proceso imparcial y son evidentes las imperfecciones que presentan la estructura y jerarquía del sistema disciplinario, en las que de alguna manera la academia debe interesarse, con el fin de aportar conocimiento a través de investigaciones que permita abordar el tema para ayudar a resolverlo.

De acuerdo a lo antes narrado, es necesario manifestar que la realidad es que los principios constitucionales mueven los Estados, y estos, según su modelo de Estado, caracterizan la forma organizacional que tendrá el mismo. Es importante también afirmar que el principio de imparcialidad es fundamental para el Estado social de derecho porque ayuda a mantener un orden social, a través de la sanción a los servidores públicos cuando estos van en contra de los derechos, deberes 
y postulados constitucionales y legales, que para el caso Colombiano recae en la Procuraduría General de la Nación (Suarez, 2015).

Finalmente, vale la pena manifestar, que el principio de imparcialidad se relaciona con los derechos humanos más básicos del hombre, tiene que ver con los mínimos requeridos para la aplicación de una justicia que implemente la dignidad humana, la presunción de inocencia, el derecho a ser juzgado por un juez imparcial y, sobre todo, garantizar que los procedimientos que se implementan desde el servicio público sean transparentes, objetivos, neutrales y completamente imparciales.

A pesar de que la imparcialidad está contenida como uno de los principios constitucionales para el servicio público y está estipulada en la norma disciplinaria, es decir, regulada constitucionalmente y legalmente, más que estar contenida allí, la imparcialidad tiene dos componentes: el elemento objetivo y el elemento subjetivo, para que no se quede simplemente en "apariencia de imparcialidad", unas que dicen que es posible ser completamente imparcial, siguiendo las normas, y dejando de lado los preconceptos, y otras donde se establece que la imparcialidad no puede darse de forma natural, puesto que el ser humano tiene presaberes culturales, sociológicos, éticos.

\section{Conclusiones}

Lo primero que hay que decir es que hay autores que defienden la imparcialidad y la consideran un elemento esencial, un valor que caracteriza a los jueces al momento de tomar una decisión. Por otro lado, hay posturas que sostienen que la imparcialidad es un principio casi imposible de cumplir, por no ser propia del juicio de los seres humanos. Los jueces no pueden ser imparciales, pues siempre interferirán sus pensamientos y gustos a la hora de tomar decisiones.

La decisión de imponer un castigo está asociada al poder y la facultad sancionatoria del Estado. Este tipo de castigo evolucionó de acuerdo al tiempo y las exigencias sociales, hasta tener una legislación especial para los representantes del Estado (los servidores públicos) a quienes por la relación especial de sujeción se les aplican normas de tipo disciplinar con la finalidad de proteger el servicio público y los postulados 
constitucionales y legales. Aparece el principio de imparcialidad como elemento esencial de la organización estatal y protector de los derechos de las personas y del Estado social de derecho.

El derecho disciplinario es considerado una rama independiente y autónoma, por lo que el principio de imparcialidad es imprescindible a la hora de aplicar una sanción. Existen desacuerdos entre lo planteado por la Corte IDH y la Corte Constitucional; por un lado, la Corte IDH ha dicho que cada Estado, a través de su justicia, debe garantizar la independencia e imparcialidad del juez; por el otro, la Corte Constitucional toma el principio de imparcialidad y lo complementa con el principio de debido proceso y derecho a la igualdad ante la ley.

\section{Referencias}

Ardila Quiroz, L. E., Oviedo Castro, J. C., E Pineda Álvarez, O. (2010). Naturaleza jurídica del derecho disciplinario de los servidores públicos en Colombia. Universidad Libre de Colombia.

Brito, Ruiz, Fernando. (2012). Régimen Disciplinario. Legis.

Congreso de la República. Ley 734 de 2002, Por la cual se expide el Código Disciplinario Único (5 de febrero de 2002). https://www.alcaldiabogota. gov.co/sisjur/normas/Normal.jsp?i=4589

Colombia, Congreso de la República. Ley 1952 de 2019, Por medio de la cual se expide el código general disciplinario se derogan la ley 734 de 2002 y algunas disposiciones de la ley 1474 de 2011, relacionadas con el derecho disciplinario (28 de enero de 2019). http://www.secretariasenado.gov.co/ senado/basedoc/ley_1952_2019.html

Constitución Política de Colombia. [Const.] (1991). Legis.

Daza, M. (2011). La naturaleza jurídica del derecho disciplinario ¿autónoma e independiente? Actualidad jurídic, 57-63. https://www.uninorte.edu.co/ documents/4368250/4488389/La+naturaleza+jur\%C3\%ADdica+del+derecho+disciplinario+iautónoma+e+indenpendiente $\% 27 / 37 c 6 e e 7 d-e 92$ c-46ed-b1be-849d4a2a3023

Díaz, L. (2007). Algunas consideraciones sobre el castigo. Una perspectiva desde la sociología. Derecho Penal y Criminología, 28(83), 141-176. https:// revistas.uexternado.edu.co/index.php/derpen/article/view/971 
Dworkin, R. (2015). El imperio de la Justicia. Universidad Nacional de México (UNAM).

Foucault, M. (1975). Vigilar y castigar. Nacimiento de una prisión. Editores Argentina.

Forero, J. (2009). El control disciplinario Clave en la construcción de un Estado constitucional, social y democrático de derecho. Criterio Jurídico Garantista, 1(1), 114-119. http://dx.doi.org/10.26564/21453381.297

Gómez, C. (2008). Asuntos disciplinarios: Praxis y jurisprudencia. Ediciones Jurídicas Axel.

Gómez, C. (2017). Dogmática del Derecho Disciplinario. Universidad Externado de Colombia.

Gutiérrez, F., E Escobar, C. (2010). La teoría del delito y la teoría de la falta disciplinaria en el derecho positivo colombiano (análisis comparativo). Derecho y Realidad, 8(16), 219-236. https://revistas.uptc.edu.co/index.php/ derecho_realidad/article/view/4948

López Nuila, J. A., E Molina Méndez, J. C. (2013). Los derechos humanos y la garantía del amparo: análisis histórico, doctrinal y jurisprudencial. Universidad Tecnológica de El Salvador.

Maquiavelo, N. (1895). El Príncipe. Universidad Autónoma de Nuevo León. Montesquieu. (1748). El espíritu de las leyes. Universidad de Sevilla.

Prieto Monroy, C. (2003). El proceso y el debido proceso. Vniversitas, 52(106), 811-823. https://revistas.javeriana.edu.co/index.php/vnijuri/article/ view/14836

Roa, D. (2012). La jurisprudencia del Consejo de Estado y sus recientes aportes al derecho disciplinario. Derecho Penal y Criminología, 33(94), 97-126. https://revistas.uexternado.edu.co/index.php/derpen/article/view/3261

Rousseau, J. J. (1778). El Contrato Social. Biblioteca Digital Instituto Latinoamericano de la Comunicación Educativa ILCE (Edición Digital).

Steiner, C. (2014). Convención Americana sobre Derechos Humanos comentada. Fundación Konrad Adenauer.

Schimitt, C. (1932). El concepto de lo político. Alianza Editorial.

Suarez Bohórquez, J. E. (2015). La culpabilidad disciplinaria en los fallos de la Procuraduría General de la Nación y su interpretación jurídica y valoración probatoria de cara al estándar de "buen servidor público". (Tesis de Maestría, Universidad Nacional de Colombia, Bogotá). https://repositorio.unal.edu. co/handle/unal/55661 